\title{
OSTEOMYELITIS OF THE SPINE FOLLOWING LUMBAR PUNCTURE
}

\author{
BY \\ LEONARD FINDLAY, M.D., D.Sc., and F. H. KEMP, M.R.C.P., D.M.R.E. \\ (From the Radcliffe Infirmary, Oxford)
}

\begin{abstract}
Case report
The patient was a boy aged one month who was admitted to the Radcliffe Infirmary, Oxford, on March 6, 1942. He was the second child of healthy parents, born on February 2 with a weight of $6 \mathrm{lb}$. after a normal pregnancy. He was breast fed and progressed satisfactorily till the age of three weeks when he developed a cold in the head and a rash on the face and buttocks. At first the child did not seem seriously upset, for he continued to take his feeds well without any vomiting and to have regular and normal evacuation of the bowel. Two or three days before coming under observation, however, he had been manifestly ill, refusing the breast and seeming breathless: and for twenty-four hours the left eye had been discharging.
\end{abstract}

On admission to hospital he was noted to be a small, wasted and dehydrated infant weighing $5 \frac{1}{2} \mathrm{lb}$. The temperature (rectal) was subnormal $-96^{\circ} \mathrm{F}$. There was much excoriation of the cheeks, a profuse nasal discharge, purulent conjunctivitis of the left eye and ulceration of the buttocks, scrotum and legs, apparently of a septic nature. Examination of the chest revealed poor air entry and scme moist and dry râles generally, but no dullness to percussion. The abdomen was distended with the liver palpable one finger-breadth kelow the costal margin, but the spleen could not te felt. There were no abnormal neurological signs. The urine presented a deposit of urates, tut contained no albumin, blood or pus.

Blood count: Hb. 100 per cent.. red blood cells $4,240,000$, white blcod cells 4,000 per c.mm.

A provisional diagnosis of generalized bronchitis following an upper respiratory infection in a marantic and tadly cared for infant was made. Next day. however, slight nuchal rigidity was present. and during a routine examination the child had two short convulsive seizures. each lasting about a minute. This change in the clinical picture raised the question of meningitis and the necessity fer an examination of the cerebro-spinal fluid. Lumbar puncture was attempted on two cccasions. but no fluid was obtained. and at the time. frcm the grating of the needle, the operator was conscious that the vertebral column had teen injured.

On the following day (March 8) the child seemed better: there had teen no recurrence of convulsions. the conjunctival discharge was less profuse, the septic condition of the skin had improved. he was taking his feeds well and had gained some weight: there was, however, slight fever $(101 \cdot 6$ F.). Although the child's general condition continued to improve. fever, varying tetween $101^{\circ} \mathrm{F}$. and $103^{\circ} \mathrm{F}$.. persisted. and on March 11, i.e. four days after the attempted lumbar puncture, the needle track was observed to have become infected, and was discharging pus from which the staphylococcus aureus was grown. On this date the bacteriologist reported that the discharge from the eye revealed the presence of a gramnegative diplococcus indistinguishable from the gonococcus, and in consequence sulphapyridine (M \& B 693) was administered by mouth in addition to argyrol 10 per cent., which had been applied locally to the eye since admission. On this date it was also learned that the Wassermann and Kahn tests were negative.

In spite of the administration of sulphapyridine. fever persisted and the local infection at the seat of the lumbar puncture continued to advance. By March 14 a fluctuant swelling requiring incision had developed. Nevertheless, the child's general condition had improved still further, the eye had cleared. the septic state of the skin had almost completely healed, he had continued to take his feeds well and to increase in weight. In view of this general improvement, the apparent localization of the infection to the subcutaneous tissues surrounding the needle track, and especially because the etiological organism was the staphylococcus aureus against which sulphapyridine is not particularly effective, treatment with this drug was interrupted. Thereafter, the local infection rather improved, probably because of the incision of the abscess and the better drainage, and within three days fever had disappeared. However, three days later (March 25) fever returned and examination now revealed swelling of the lumbar region of the spinal column and an x-ray picture showed destruction of the bodies of the second and third lumbar vertebrae and the intervening intervertebral disc space. Treatment with sulphathiazole was now instituted and continued for six days. Within twelve hours of the presentation of this drug the fever subsided. and with the exception of a slight and occasional rise during the following two weeks, the temperature continued within normal limits. In spite of the absence of fever, the local condition of the spine persisted unchanged. and on March 30 , oedema of the left leg below the knee made its appearance. and a few days later. the right leg was also noted to be oedematous. The swelling of the left leg extended to the thigh and lower abdomen with considerable glandular enlargement in the groin. Finally, the scrotum was also oedematous. At this stage the left femur felt thickened and x-ray examination revealed periostitis of the shaft, and subluxation of the left hip joint. On April 13 a swelling on the palmar aspect of the second finger of the left hand was observed which $x$-ray examina- 
tion showed to be connected with osteitis of the middle phalanx. This swelling rapidly increased in size, became fluctuant and on incision discharged pus from which staphylococcus aureus was isolated. By this time the swelling of the lumbar spine had further increased and there was present an angular curvature, and on April 21 a skiagram showed great extension of the disease, the bodies of the second and third lumbar vertebrae having almost completely disappeared (fig. 1).

Although the present communication is for the purpose of drawing attention to the risks associated with, and an unusual sequel to, lumbar puncture, it

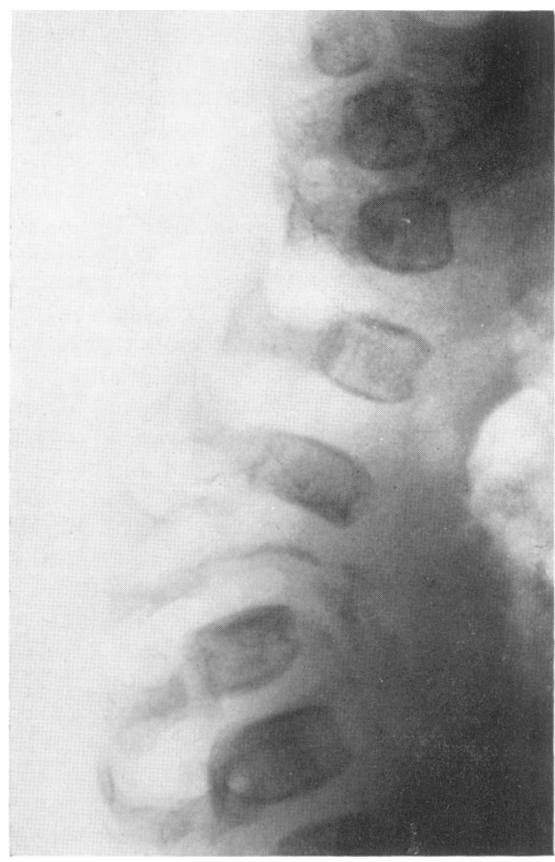

FIG. 1.-Skiagram showing almost complete disintegration of bodies of 2 nd and 3 rd lumbar vertebrae with persistence of the spinous processes.

is also of interest to relate that with the institution of treatment with penicillin such a serious and apparently hopeless complication was recovered from. This treatment, begun on April 25, was conducted under the guidance of Professor Florey, who no doubt will incorporate the details of the dosage and the subsequent progress in the general report of his researches with this drug. Hence it may suffice to say briefly that the child, excepting for a further abscess, which developed in the nape of the neck just below the occipital protuberance from which the staphylococcus was also recovered, and which was first noticed two days after the inception of the penicillin treatment, made a good recovery. The various septic foci steadily improved, the sinus at the seat of the lumbar puncture healed, the swelling and deformity of the lumbar region of the spinal column gradually disappeared and the swellings of the finger and at the nape of the neck subsided. Radiological examination showed a return to the normal conditions in the leg and hand and some new bone formation at the situation previously occupied by the bodies of the second and third lumbar vertebrae. The temperature, as previously mentioned, remained at a normal level, the child continued to put on weight and began to laugh and to smile and develop as a normal baby should.

\section{Comment}

The course of events in this case would seem to leave no doubt regarding the cause of the calamity. As the result of the attempt at lumbar puncture, a wound of the skin was made in a region not far removed from a definitely septic focus (the buttocks) and it became infected. Although a bacteriological examination of the primary septic condition of the skin was not made, it is not improbable that it was of a staphylococcal nature. Moreover, during the attempt at lumbar puncture, the operator was conscious that one of the vertebrae had been injured, so that a direct track from the skin surface to the vertebral column was produced. The operation wound became septic and the infection travelled along the track of the needle to settle down in the injured vertebral body, with the development of osteomyelitis. Later, there ensued a blood infection with the metastatic foci in the middle phalanx of the second finger of the left hand, in the left femur and left hip joint and in the deep tissues of the neck. It might be considered fortunate that in this case the lumbar puncture was a so-called dry tap, and that the spinal canal was not opened, otherwise a meningitis would have been a further and still more serious complication.

That the vertebral column may be impinged upon by the point of the needle is well known to all familiar with the operation of lumbar puncture, and Pease (1935) has demonstrated, by means of skiagrams with the needle in situ, that both the intervertebral discs and the vertebral bodies may be injured during the operation. Pease found that when the body is flexed, the usual posture during the operation, the needle enters the intervertebral disc, but if the body is not arched, the neadle pierces the body of the vertebra. However, in spite of the frequency with which the vertebral column must be injured, especially in the case of the smaller spinal canal of the infant and young child, mishaps ascribable to this factor have seldom been recorded. One would not be surprised if the injured focus in the vertebral column became a nidus for infection, just as is frequently encountered, and indeed is always feared, in connexion with any injury during an infective process. And when it is appreciated that the needle must often pass through an infective focus in the pia arachnoid before reaching the body of the vertebra, the dearth of such sequelae seems all the more remarkable. In a fairly extensive experience of this operation by one of us, this is the first instance of such a nature that he has observed.

The literature, ever since the introduction of this diagnostic procedure, abounds with records of accidents, varying from transient headache and vertigo to sudden death, following lumbar puncture. For the most part, they have been attributed to altera- 
tions in the pressure of the cerebro-spinal system consequent on the abstraction of the fluid or to mechanical irritation of the meninges. Occasionally instances of an inflammatory reaction, viz. meningitis (Levy and Cohen, 1925; Reynolds and Wilson, 1934; Symonds, 1925), due more frequently to an endogenous than to an exogenous source of infection (Pray, 1941; Weed et al., 1919), are recorded, but it was not until 1924, some forty-three years after the introduction of the operation, that injury to the vertebral column first finds mention as the cause of any disability following lumbar puncture.

In 1924 Billington recorded thirty-five cases of spondylitis following cerebro-spinal fever. In all, numerous lumbar punctures had been performed. In these cases the chief complaint was of stiffness and pain in the lumbar region which had developed during, or soon after, the attack of meningitis. In sixteen cases the manifestations were purely subjective; in five cases there was present in addition to the pain, definite rigidity of the lumbar spine, and in fourteen cases there was present, as well as the symptoms and physical signs, radiological evidence of disease of the vertebral column. This latter consisted of lipping, spurring and other hypertrophic changes of the third, fourth or fifth vertebrae in all cases; in seven cases there was also thinning or destruction of the disc between the third and fourth or the fourth and fifth lumbar vertebrae, and in one case general spondylitis deformans.

Billington states that he had never observed this clinical picture apart from cerebro-spinal fever and he concluded that the mischief was due to infection by the meningococcus. He recalls that it is not unknown for this organism to cause arthritis and he considered that the infection had been carried to the vertebrae by means of the lumbar puncture needle. As he remarks, "the spinal puncture may easily afford a direct means of inoculating the lower vertebrae and discs with the meningococcus, and in view of the location of the pathologic conditions in the cases recorded, it appears probable that it is an important etiological factor. The two cases in which there were pathological changes in other regions may represent metastatic infections' (as happened in the present case), "such as occur in the involvement of joints of the extremities, though apparently less frequently.'

Subsequent observations, however, have cast doubt on Billington's thesis that changes such as were observed by him are necessarily due to infection by the meningococcus, and suggest that they may be caused by some other infective agent, or that they may have a purely mechanical basis.

In 1935 Pease recorded three instances in which an exactly similar pathological picture (pain and rigidity of the lumbar spine with radiological evidence of thinning of an intervertebral disc and sclerosis and lipping of the adjacent vertebral bodies) followed lumbar puncture. Pease's patients were children, but only one was suffering from cerebrospinal fever. One of the children had infantile paralysis, and in the other child lumbar puncture was performed for the production of an encephalogram.
Pease naturally doubted that the mischief had a bacterial basis. He ascribed the changes to mechanical strain consequent on the puncture of the intervertebral disc with escape of the nucleus pulposus and removal of the normal cushion between the individual vertebral bodies. In support of his argument he stresses the thinning of the discs, which to him is a constant feature, and he recalls the work of Keyes and Compere (1932) who showed experimentally in the dog, (a) that if the disc and neighbouring part of the vertebral body are injured by a scalpel the nucleus pulposus may escape into the spongiosa of the vertebra and produce the condition known as Schmorl's node and (b) that if the disc were incised and the nucleus allowed to escape the disc becomes narrowed and the edges of the adjacent vertebrae become sclerosed and lipped.

It is interesting in this connexion to record that Compere (during a discussion following Pease's communication) said that his experiments referred to by Pease were not comparable with lumbar puncture, as he incised the fibrous capsule of the disc with a scalpel, and he doubted if the nucleus pulposus could escape through such a small wound as that caused by a lumbar puncture needle. At any rate in the dog he could not get results by needle puncture which he obtained by scalpel incision. Compere also said that he was suspicious that in some of the adult cases recorded 'the pathologic changes in the disc may have been the reason for lumbar puncture and not a result of it.' Another important point germane to this discussion was raised at the same time by Barber, who stated that "Todd and Pyle, in a qualitative study of the vertebral column by direct and roentgenoscopic methods, found the vertebral dimension of the intervertebral discs to vary from 8 to $19 \mathrm{~mm}$. The disc between the second and third lumbar vertebrae averaged $11.3 \mathrm{~mm}$. with a range from 8 to $14 \mathrm{~mm}$.; the disc between the third and fourth lumbar vertebrae averaged $12.4 \mathrm{~mm}$. with a range from 8 to $16.5 \mathrm{~mm}$. and the disc between the fourth and fifth lumbar vertebrae averaged $14 \cdot 8$ $\mathrm{mm}$. with a range from 11 to $19 \mathrm{~mm}$.' Todd and Pyle also found that a lateral roentgenogram gave the measurement of a disc but that an antero-posterior roentgenogram did not.*

In 1936 Milward and Grout reported five instances in which the same clinical syndrome followed lumbar puncture for the induction of spinal anaesthesia. These authors, in view of the nature of their material, also doubted that the changes were the result of an infective process and, like Pease, were inclined to ascribe the lesions to mechanical forces. Whilst they admit that the fons et origo of the lesion in the child may be, as Pease believed, the disappearance of the intervertebral disc, they are doubtful if this is so in the case of the adult. They do not think that a needle puncture is sufficiently large to allow of the escape of the much smaller and better protected nucleus pulposus at this time of life, but are of the opinion that the trauma of the annulus fibrosa by the needle sets up ' an inflammatory reaction with a consequent weakness in the fibrous wall' and in this way permits ' of a gradual escape of the nucleus pulposus.' This view they consider is borne out by the x-ray appearances in three of their cases, "where

\footnotetext{
* In a large series of cases of excision of posterior prolapse of the nucleus pulposus for sciatica and followed for long periods after the operation, one of us (F. H. K.) has never observed any radiological change in the adjacant vertebral bodies.
} 
there was only slight erosion of the articular surfaces at the first examination but a complete involvement of the whole joint at a subsequent examination a month or two later.'

The only other communication found dealing with this subjèct is a case record by Gillman (1940). This refers to a luetic child of fourteen years of age who, after three unsuccessful attempts at lumbar puncture three years previously, complained of severe pain in the back. X-ray examination four days after the operation revealed nothing abnormal, but when repeated one month later because of the persistence of the pain and the appearance of rigidity, narrowing of the space between the third and fourth lumbar vertebrae and relative widening between the second and third and the fourth and fifth was evident. With immobilization of the spine the pain and rigidity ultimately disappeared, but seventeen months after the attempted lumbar puncture, there was discernible on radiological examination erosion of the adjacent articular surfaces of the fourth and fifth and of the second and third vertebrae. This author concludes that the sequence of events is as suggested by Pease.

Whatever be the truth about the etiology of the examples of acute and chronic spondylitis following lumbar puncture previously reported, there can be no doubt that in the present case bacterial infection of the injured spine was the dominating factor.

\section{REFERENCES}

Billington, R. W. (1924). J. Amer. med. Ass., 83, 683. Gillman, M. (1940). J. Bone Jt. Surg., 22, 980.

Keyes, D., and Compere, E. J. (1932). Ibid., 15, 897.

Levy, I. I., and Cohen, A. E. (1925). J. Amer. med. Ass., 85, 1968.

Milward, F. J., and Grout, J. L. A. (1936). Lancet, 2, 183.

Pease, C. N. (1935). Amer. J. Dis. Child., 49, 849.

Pray, L. G. (1941). Ibid., 62, 295.

Reynolds, K. E., and Wilson, G. (1934). J. Amer. med. Ass., 102, 1460

Symonds, C. P. (1925). Lancet, 1, 434.

Weed, L. H., Wegeforth, P., Ayer, J. B., and Felton, L. D. (1919). J. Amer. med. Ass., 72, 190. 